\title{
Research Paper: Prognosis and Complications of Attempted Suicidal Hanging
}

\author{
Azadeh Memarian' $^{1}$ (D), Kamran Aghakhani ${ }^{1}$, Babak Soltani², Siamak Soltani ${ }^{{ }^{*}}$ (iD
}

1. Department of Forensic Medicine, Iran University of Medical Sciences, Tehran, Iran.

2. Infectious Diseases Research Center, Kashan University of Medical Sciences, Kashan, Iran.

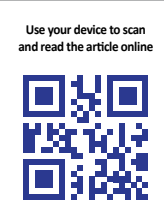

Critation: Memarian A, Aghakhani K, Soltani B, Soltani S. Prognosis and Complications of Attempted Suicidal Hanging. International Journal of Medical Toxicology and Forensic Medicine. 2019; 9(4):191-198.

: https://doi.org/10.32598/ijmtfm.v9i4.23172

\section{(i) (8)}

Article info:

Received: 13 Mar 2019

First Revision: 25 Mar 2019

Accepted: 03 Aug 2019

Published: 01 Oct 2019

\section{Keywords:}

Suicidal hanging, Prognostic factor, Respiratory distress syndrome

\section{A B ST RACT}

Background: Hanging is a form of strangulation, in which the body is suspended through the neck and the weight of the body acts as a constricting force. This study assessed various factors on the outcome of hanging and identification of prognostic factors related to the outcomes.

Methods: Ninety-nine hanging victims from 1995 to 2015 in Iran were evaluated; then, variables such as the cause of death, distribution of mortality, duration of hospitalization, substance abuse consumption, respiratory distress, and cerebral edema were studied in these people. Finally, the data were analyzed.

Results: Major cases of suicide by hanging were men. In connection with prognosis, about $12 \%$ of the deaths occurred in men and about $21 \%$ were represented in women. More importantly, in the matter of suspension, the model was largely incomplete to complete. Also, the outcomes of pulmonary stress and cerebral edema were recognized in association with the type of hanging and mortality prognosis.

Conclusion: Only two risk factors, including loss of consciousness at the time of entry into the medical center, as well as the complete suspension, would be predictive operations of death and unsuccessful revival.

\section{Introduction}

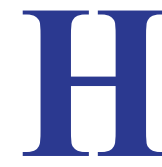

anging is a form of strangulation, in which the body is suspended through the neck and the weight of the body acts as a constricting force $[1,2]$. So, hanging is considered as a method of attempting suicide with a harmful impact and has a significant growth in some countries such as Australia and New
Zealand $[3,4]$. The fatality rate in hanging is over $70 \%$; thus, there is little chance to change one's mind right after suspension $[2,5,6]$. In recent decades, the rate of suicidal hanging has approximately doubled in some developed countries, especially for men [3].

Generally, hanging can be performed in two forms, including complete and incomplete [7]. Complete hanging is accomplished in a situation, in which the body is

\footnotetext{
* Corresponding Author:

Siamak Soltani, MD.

Address: Department of Forensic Medicine, Iran University of Medical Sciences, Tehran, Iran.

Tel: +98 (912) 0704959
}

E-mail:soltani.s@iums.ac.ir 
entirely suspended and the feet are above the ground. While in incomplete hanging, the feet or toes have contact with the ground. Suicidal hanging is associated with a suspension, in which a person with a band around his neck jumps off support (e.g. a chair) [8].

Although suicidal hanging could be mortal, in some cases, patients would recover and discharge from the hospital, who are termed as 'near hanging' [9]. Thus, the number of hanging victims represents an increase in intensive care units [10-12]. Postponed deaths in near hanging individuals are related to the complexity of hanging. Neurologic and respiratory complications are the consequences of attempted suicidal hanging. Pulmonary distress is one of the important complications resulting from pulmonary edema, acute respiratory distress syndrome, and airway obstructions that lead to immediate airway intubation. On the other hand, suicidal hanging results in the compression of the airway or cervical vascular leading to cerebral edema [13].

The aim of the present study was to evaluate the variable factors influencing outcomes in hanging and complications for patients presenting to the hospital following a hanging injury.

\section{Materials and Methods}

\section{Patients}

In this retrospective study, 99 injured patients, who committed a suicidal hanging, were studied. Among the patients, 85 were male (85.8) and 14 were female (14.2). Variables such as mortality rate, the mean hospitalization duration, hanging pattern, Glasgow coma score (GCS), and the severity of respiratory distress and cerebral edema of the patients were evaluated.

\section{Inclusion and exclusion criteria}

Cases, who were referred to Hafte-tir medical center from March 1995 to 2015, were examined. The exclusion criteria of the project included the lack of defects in the patients' demographic data, incomplete recorded data in the hospital information system, and incomplete recorded clinical and physician information for each patient.

\section{Performance}

Information was completed through the preset checklist, including demographic information, GCS on admission, type of hanging, ICU length of stay, P/F ratio from the admission arterial blood gas, and brain $\mathrm{CT}$ in order to diagnose pulmonary distress and cerebral edema, respectively; all of them are obtained by project partners from the patients' records.

\section{Ethical consideration}

In terms of ethics, the project was done under the approval of the Ethics Committee of Hafte-tir Hospital and along with the declaration of Helsinki. Also, protecting the confidentiality of patient information was considered without mentioning the names of patients during this research.

\section{Data analysis}

The results were expressed as mean and Standard Deviation (SD) for quantitative variables and as a percentage for qualitative variables. Continuous variables were compared by t test. The Chi-square test was used to compare the qualitative variables. In addition, the multivariate logistic regression analysis was used to determine factors associated with mortality and the results were presented in odds ratio (95\% confidence interval). The data were analyzed, using SPSS statistical software, version 21.0 (SPSS Inc., Chicago, Illinois, USA).

\section{Result}

Generally, 99 injured patients $(85.8 \%$ male and $14.2 \%$ female) were studied. The Mean \pm SD age was $31.55 \pm 14.58$ (age range of 13-64 years) for men and $33.36 \pm 11.41$ (age range of 18-56 years) for women.

In terms of GCS on the admission of victims to the health center, the Mean \pm SD of GCS was $7.91 \pm 3.18$ and $6.82 \pm 2.60$ for men and women, respectively (Figure 1). However, P-value was 0.245 , showing no significant difference. Results presents the frequency of mortality. The mortality rate in women (21.4) was higher than men (12.9), but this difference was not statistically significant $(\mathrm{P}=0.413)$.

The Mean \pm SD length of ICU admission was $5.94 \pm 4.09$ days in males and 6.86 \pm 5.63 days in females (Figure 2), while there was no statistically significant difference between the sexes $(\mathrm{P}=0.465)$. The pattern of suspension in two forms of complete and incomplete was studied for both sexes (Table 1). The percentage of complete suspension in men and women was $12.9 \%$ and $14.3 \%$, respectively. While incomplete suspension had occurred in $87.1 \%$ of men and $85.7 \%$ of women with no significant difference $(\mathrm{P}=0.89)$. 


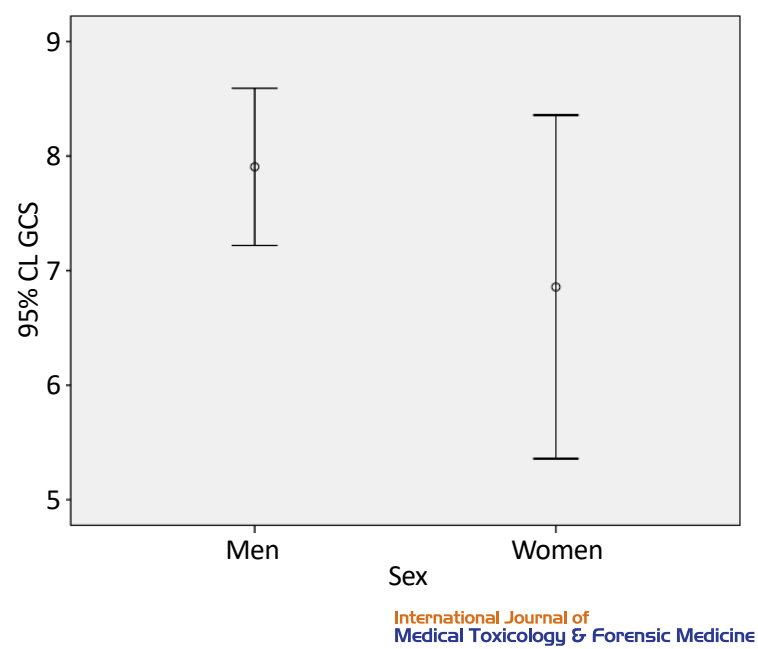

Figure 1. The mean of GCS of men and women admission

In addition, $96.5 \%$ of surviving persons and $28.6 \%$ of dead ones represented incomplete hanging (Table 2). Consequently, there was a statistically significant difference between the type of hanging and prognosis $(\mathrm{P}<0.0001)$.

The Mean \pm SD level of consciousness or GCS on admission was $8.34 \pm 2.95$ for surviving people and $4.21 \pm 1.12$ for dead people. Also, the Mean \pm SD duration of hospitalization in ICU for surviving and dead patients was $6.47 \pm 4.42$ and $3.64 \pm 2.62$ days, respectively. Based on Table 3, there was a significant difference between not only the levels of consciousness and prognosis $(\mathrm{P}<0.0001)$ but also the mean duration of hospitalization and prognosis $(\mathrm{P}=0.02)$. Also, the history of the patient's addiction to various substance abuse such as opium and amphetamines was studied (Figure 3).

Totally, factors linked to prognosis were assessed by a multivariate logistic regression model (Table 4). Among these factors, GCS and the pattern of suspension represented a relationship with the death of injured people.

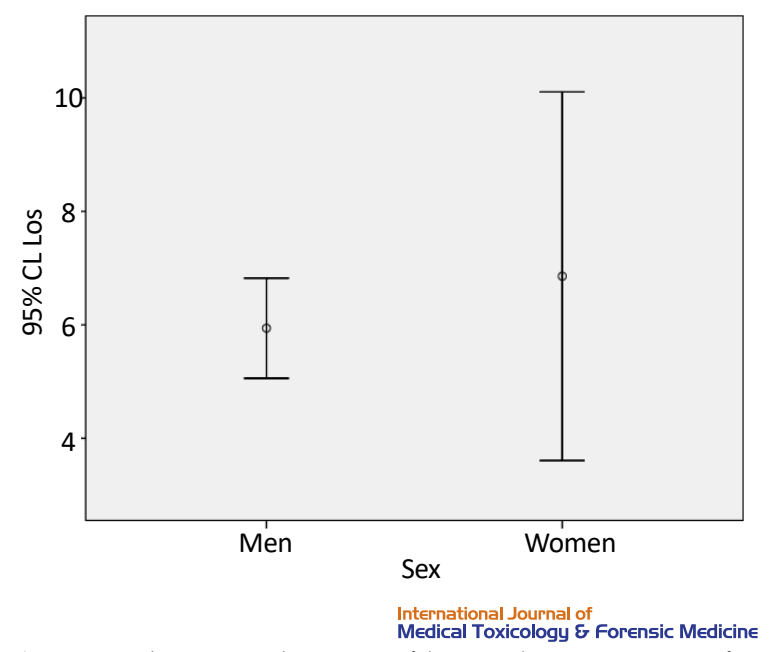

Figure 2. The mean duration of hospitalization in ICU for men and women

Whereas, other factors had no connection with the individual's mortality.

In addition, the severity of post-obstructive pulmonary distress and cerebral edema were investigated based on different variables (Tables 5 and 6). Pulmonary distress was diagnosed in 30 (33.3\%) of 99 admitted patients, who attempted hanging; 13 (43\%) of 30 patients died from pulmonary distress and $1(1.4 \%)$ death occurred in 69 patients without pulmonary distress. There was a statistically significant difference among the severity of pulmonary distress and type of hanging, addiction, mean GCS score, and the mean length of ICU stay (Table 5). Based on the $\mathrm{P} / \mathrm{F}$ ratio of arterial blood gas at presentation, the severity of pulmonary distress was classified into different categories; $\mathrm{P} / \mathrm{F}<100$ was classified as severe and $\mathrm{P} / \mathrm{F}>300$ as mild pulmonary distress. Mortality was $100 \%(7 / 7)$ in patients with severe pulmonary distress and no mortality was detected (0/5). The univariate analysis demonstrated a statistically significant difference between mortality and severity of pulmonary distress $(\mathrm{P}<0.001)$.

Table 1. The pattern of suspension for men and women

\begin{tabular}{cccc}
\hline & \multicolumn{2}{c}{ Frequency (\%) } \\
\cline { 2 - 3 } Pattern of Suspension & \multicolumn{2}{c}{ Sex } & Pale \\
\cline { 2 - 3 } & $74(87.1)$ & Female & 0.89 \\
\hline Incomplete suspension & $11(12.9)$ & $2(14.3)$ & - \\
\hline Complete suspension & $85(100)$ & $14(100)$ & \\
\hline
\end{tabular}


Table 2. Frequency distribution of hanging on prognosis

\begin{tabular}{|c|c|c|c|}
\hline \multirow{3}{*}{ Type of Hanging } & \multicolumn{2}{|c|}{ Frequency (\%) } & \multirow{3}{*}{$\mathbf{P}$} \\
\hline & \multicolumn{2}{|c|}{ Prognosis } & \\
\hline & Alive & Dead & \\
\hline Incomplete hanging & $82(96.5)$ & $4(28.6)$ & \\
\hline & & & $<0.0001$ \\
\hline Complete hanging & $3(3.5)$ & $10(71.4)$ & \\
\hline Total & 85 (100) & $14(100)$ & - \\
\hline
\end{tabular}

International Journal of
Medical Toxicology \& forensic Medicin

Table 3. The mean level of consciousness on admission and duration of hospitalization based on prognosis

\begin{tabular}{ccc}
\hline & \multicolumn{2}{c}{ Mean \pm SD } \\
\cline { 2 - 3 } Parameters & \multicolumn{2}{c}{ Prognosis } \\
\cline { 2 - 3 } & Survived & Dead \\
\hline Level of consciousness & $8.34 \pm 2.95$ & $4.21 \pm 1.12$ \\
Duration of hospitalization in ICU & $6.47 \pm 4.42$ & $3.64 \pm 2.62$ \\
\hline
\end{tabular}

International Journal of
Medical Toxicology \& forensic Medicine

Cerebral edema was diagnosed in $21(21.2 \%)$ of 99 admitted patients; $10(47.6 \%)$ of 21 cases died. In comparison to $4(5.1 \%)$ of 78 cases without cerebral edema, this difference was significant. The Mean \pm SD age of patients with cerebral edema was $32 \pm 13$ that did not differ significantly between the two groups. Complete hanging was found in $8(38 \%)$ of 21 patients with cerebral edema; there was a statistically significant difference between cerebral edema and the type of hanging in this study (Table 6). Cerebral edema was not affected by age, sex, addiction, mean GCS, and length of ICU stay.

\section{Discussion}

The purpose of this study was not only evaluating the variable factors influencing outcomes in hanging but also investigating the patient's prognosis and complications in a hanging injury. Based on this research, the ma-

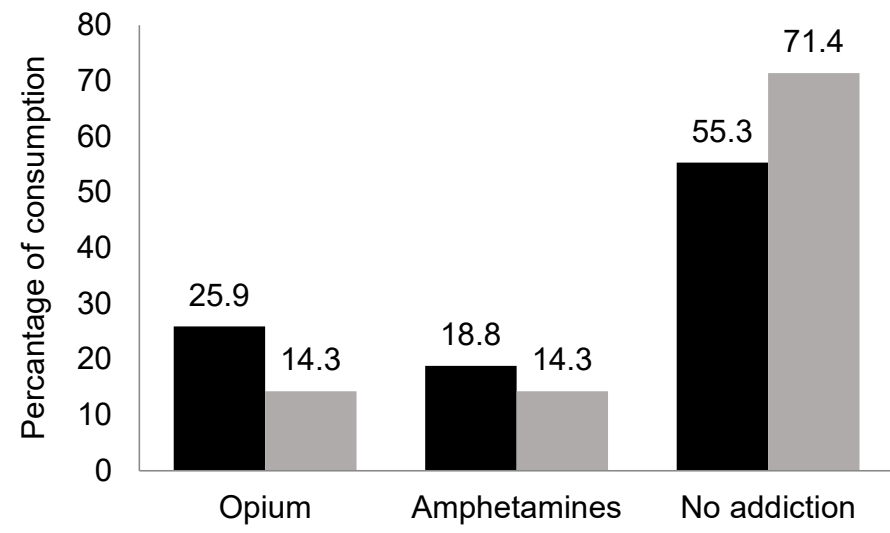

Type of substance abuse cunsumption

Figure 3. The frequency distribution of substance abuse in women and men (Black column: Men; Gray column: Women) 
Table 4. Multivariate logistic regression models to determine factors associated with death

\begin{tabular}{cccccc}
\hline Variations & B & S.E. & Wald & P & OR \\
\hline Age & -0.033 & 0.044 & 0.550 & 0.458 & 0.968 \\
Sex & 2.016 & 1.908 & 1.116 & 0.291 & 7.510 \\
GCS & -2.181 & 0.844 & 6.681 & 0.010 & 0.113 \\
Type of suspension & 10.852 & 4.746 & 5.229 & 0.022 & 5.164 \\
\hline Addiction & 3.041 & 2.657 & 1.310 & 0.252 & 20.925 \\
\hline
\end{tabular}

jor cases of suicide by hanging were men, the number of whom was more than two-thirds of injured admissions. The study of Uzun et al. also outweighed the occurrence of hanging in men by $70 \%$ [14]. In addition, according to Bayramoglu's study, the rate of suicide in men was higher than women, and other elements such as age had no effective influence on suicide attempts [15]. Similarly, the results of our study demonstrated no significant relationship between age and hanging attempt.

Regarding the prognosis after attempts, Matsuyama et al. stated that the proportion of death among men was significantly higher than women [16]. In contrast, the result of the present study demonstrated a higher per- centage of death among women (21\%) than men (12\%); however, there was no significant relationship between mortality of hanging and gender of victims. This might be owing to the short number of patients in this study.

Moreover, regarding the type of suspension, the results of the present study demonstrated that the model was largely incomplete rather than complete. The results showed the percentage of incomplete hanging by $87.1 \%$ and $85.7 \%$ among men and women, respectively; however, in dead cases, complete hanging is significantly prevalent $(71.4 \%$ vs. $28.6 \%$ ). Similar to our results, Ambade et al. showed that the occurrence of complete hanging among both dead men and women is more than incomplete hanging [17]. In

Table 5. Risk factors and outcome data classified by the severity of post-obstructive pulmonary distress

\begin{tabular}{|c|c|c|c|c|c|c|}
\hline \multirow{2}{*}{\multicolumn{2}{|c|}{ Variations }} & \multicolumn{4}{|c|}{ P/F Ratio } & \multirow{2}{*}{$\mathbf{P}$} \\
\hline & & $<100$ & $100-200$ & $200-300$ & $>300$ & \\
\hline \multicolumn{2}{|c|}{ Mean age } & $30 \pm 17$ & $37 \pm 14$ & $29 \pm 18$ & $35 \pm 18$ & 0.663 \\
\hline \multirow{2}{*}{ Sex } & Man & $6(24)$ & $7(28)$ & $8(32)$ & $4(16)$ & \multirow{2}{*}{0.926} \\
\hline & Woman & $1(20)$ & $2(40)$ & $1(20)$ & $1(20)$ & \\
\hline \multirow{2}{*}{ Type of hanging } & Incomplete & 0 & $6(35.3)$ & $6(35.3)$ & $5(29.4)$ & \multirow{2}{*}{0.003} \\
\hline & Complete & $7(53.8)$ & $3(23.1)$ & $3(23.1)$ & 0 & \\
\hline \multirow{3}{*}{ Addiction } & Opium & $2(33.3)$ & 1 (16.7) & 1 (16.7) & $2(33.3)$ & \multirow{3}{*}{0.011} \\
\hline & Amphetamine & $2(40)$ & 0 & 0 & $3(60)$ & \\
\hline & No addiction & $3(15.8)$ & $8(42.1)$ & $8(42.1)$ & 0 & \\
\hline \multirow[b]{2}{*}{ Prognosis } & Alive & 0 & $4(23.5)$ & $8(47.1)$ & $5(29.4)$ & \multirow[b]{2}{*}{0.001} \\
\hline & Dead & $7(53.8)$ & $5(38.5)$ & $1(7.7)$ & 0 & \\
\hline \multicolumn{2}{|c|}{ Mean length of ICU stay, day } & $2 \pm 1$ & $5 \pm 2$ & $5 \pm 3$ & $5 \pm 2$ & 0.005 \\
\hline \multicolumn{2}{|c|}{ GCS } & $4 \pm 1$ & $6 \pm 3$ & $8 \pm 3$ & $8 \pm 3$ & 0.004 \\
\hline
\end{tabular}

Data are presented as frequency $(\%)$ and Mean \pm SD 
Table 6. Cerebral edema based on studying variables

\begin{tabular}{|c|c|c|c|c|}
\hline \multirow{2}{*}{\multicolumn{2}{|c|}{ Variations }} & \multicolumn{2}{|c|}{ Cerebral Edema No. (\%) } & \multirow{2}{*}{$\mathbf{P}$} \\
\hline & & Positive & Negative & \\
\hline \multicolumn{2}{|c|}{ Mean $\pm S D$ age } & $32 \pm 18$ & $32 \pm 13$ & 0.592 \\
\hline \multirow{3}{*}{ Sex } & Man & $17(20)$ & $68(80)$ & \multirow{3}{*}{0.467} \\
\hline & & & & \\
\hline & Woman & $4(28.6)$ & $10(71.4)$ & \\
\hline \multirow{3}{*}{ Type of hanging } & Incomplete & $13(15.1)$ & $73(84.9)$ & \multirow{3}{*}{$<0.000$} \\
\hline & & & & \\
\hline & Complete & $8(61.5)$ & $5(38.5)$ & \\
\hline \multirow{3}{*}{ Addiction } & Opium & $5(20.8)$ & $19(79.2)$ & \multirow{3}{*}{0.771} \\
\hline & Amphetamine & $3(16.7)$ & $15(83.3)$ & \\
\hline & No addiction & $13(22.8)$ & $44(77.2)$ & \\
\hline \multirow{3}{*}{ Prognosis } & Alive & $11(12.9)$ & $74(87.1)$ & \multirow{3}{*}{$<0.0001$} \\
\hline & & & & \\
\hline & Dead & $10(71.4)$ & $4(28.6)$ & \\
\hline \multicolumn{2}{|c|}{ Mean duration of ICU stay, day } & $5 \pm 4$ & $6 \pm 4$ & 0.623 \\
\hline \multicolumn{2}{|c|}{ GCS } & $6 \pm 3$ & $8 \pm 3$ & 0.307 \\
\hline
\end{tabular}

Data are presented as frequency (\%) and Mean \pm SD

our study, 14 cases were found dead, 10 of whom were diagnosed with complete hanging; it is notable that a statistically significant difference existed between the type of hanging and prognosis $(\mathrm{P}<0.0001)$.

Ambade et al. demonstrated that $67 \%$ of deaths in hanging are the result of complete hanging [18]. Also, many prior studies have shown the domination of complete hanging, over the incomplete hanging, in dead cases resulted by hanging [19-21]. However, Sane et al. showed the prevalence of partial (incomplete) hanging among deaths hanging cases [22]; the major part of patients of the present study with the outcome of death were those who experienced complete hanging. In general, our results imply the prevalence of partial hanging in total and prevalence of complete hanging among dead cases.

In the study of Matsuyama et al., only 3 individuals survived among 39 patients with GCS of 3 on admission. This study suggested a significant difference between GCS greater than 3 and the outcome of hanging [23]. Also, Penney et al. evaluated GCS of 42 injured victims of hanging at the scene or upon entering the hospital. Only, 7 patients with GCS of 3 were discharged from the hospital as a prognostic factor [24]. Similarly, the results of our study demonstrated a significant correlation between the level of consciousness and survival outcome.
The patients with survived and dead outcomes showed average GCS of 8.34 and 4.21, respectively, which was consistent with previous studies. In addition, Martin et al. showed that of 655 hanging injured, 14\% of attempted hanging died on arrival at the emergency department; while in our study, no death prognosis was observed on arrival. Also, they showed, similar to the present study, that survived patients demonstrated higher GCS than non-survivors [25].

The average length of ICU admission for males and females was $5.94 \pm 4.09$ and $6.86 \pm 5.63$ days, respectively, with no statically significant difference. Also, the Mean \pm SD duration of hospitalization in ICU for surviving and dead patients was $6.47 \pm 4.42$ and $3.64 \pm 2.62$ days, respectively. Likewise, Salim et al. stated that the length of ICU stay was 6 days for injured patients by hanging [26]; however, these results, like ours, were not statistically significant.

In a study conducted by Monsef Kasmaee et al., 84.8\% of victims did not show the history of substance abuse and no relationship was found between substance abuse and the outcomes of an attempt [27]. In the same way, in the present study, the number of patients with no addiction was higher than patients, who used opium or amphetamines; the analysis to find potentiality between the 
outcome of hanging attempts and history of substance abuse showed no significant correlation.

Salim et al. studied 63 attempted hanging patients of over 10 years and did not find pulmonary distress [26]. Shalini Nair et al. studied 235 patients, who attempted hanging, demonstrating $13(34.2 \%)$ deaths in the 38 patients with pulmonary distress. In our study, of 99 attempted hanging patients, $13(30.3 \%)$ of 30 cases with pulmonary distress died. In contrast to Shalini Nair et al., we demonstrated that variables, including age, gender, mean GCS score, mean length of ICU stay, and type of hanging had an influence on the severity of pulmonary distress. Similar to Nair et al., our study demonstrated a statistically significant difference between the severity of pulmonary distress and mortality [13].

Matsuyama et al. investigated some factors affecting the outcome of suicidal hanging according to their study; $1(2.1 \%)$ of 47 patients represented pulmonary distress while cerebral edema was found in $4(8.51 \%)$ of 47 patients. In the present study, 21 (21.2\%) of 99 patients had cerebral edema and $30(30.3 \%)$ of 99 cases suffered from pulmonary distress [23]. No study investigated variables affecting cerebral edema. The strong point in our study was the investigation of risk factors influencing the outcome and respiratory and neurologic complications. The limitation of this study was the low sample size. We recommend increasing the accuracy of further investigations through multi-center studies in Iran.

\section{Conclusion}

In conclusion, it can be said that many complications and risk factors were discussed in this survey. But, doing a multi-sentence survey could be more promising to increase the sample size and reach more comprehensive results. According to the results, the majority of suicides by hanging were committed by men rather than women. In the meantime, the rate of mortality was $12.9 \%$ for men and $21.4 \%$ for women. In addition, some effective factors could be considered associated with mortality, such as GCS on admission and the pattern of suspension. Also, the outcome of pulmonary distress associates with prognosis, type of hanging, addiction, mean GCS score, and mean length of ICU stay, while cerebral edema was only associated with the type of hanging and prognosis.

\section{Ethical Considerations}

\section{Compliance with ethical guidelines}

All procedures performed in this study involving human participants were in accordance with the ethical standards of the institutional and or national research committee and with the 1964 Helsinki declaration and its later amendments or comparable ethical standards.

\section{Funding}

This research did not receive any specific grant from funding agencies in the public, commercial, or not-forprofit sectors.

\section{Author's contributions}

Concept and design study: Siamak Soltani, Azade Memarian; Drafting: Kamran Aghakhani; Data analysis: Babak Soltani; Revisiting critically: Siamak Soltani; Final approval of version: Siamak Soltani.

\section{Conflict of interest}

The authors declare no conflict of interest.

\section{References}

[1] Singh R, Sharma Y, Buri S, Saini O, Joshi A, Mathur P. Attempted hanging and fracture of hyoid bone-a rare case report. Indian Internet Journal of Forensic Medicine \& Toxicology. 2014; 12(4):83-5. [DOI:10.5958/0974-4487.2014.00882.7]

[2] Reay DT, Bonnell HJ, Luke JL, Eisele JW. Correlation of circumstances with pathological findings in asphyxial deaths by hanging: A prospective study of 61 cases from Seattle, WA. Journal of Forensic Science. 1985; 30(4):1140-7. [DOI:10.1520/ JFS11055J]

[3] Wilkinson D, Gunnell D. Comparison of trends in methodspecific suicide rates in Australia and England \& Wales, 196897. Australian and New Zealand Journal of Public Health 2000; 24(2):153-7. [DOI:10.1111/j.1467-842X.2000.tb00135.x] [PMID]

[4] Beautrais AL. Methods of youth suicide in New Zealand: Trends and implications for prevention. Australian and New Zealand Journal of Psychiatry. 2000; 34(3):413-9. [DOI:10.1080/j.1440-1614.2000.00690.x] [PMID]

[5] Simounet C, Bourgeois M. Suicides and attempted suicides by hanging. Annales Médico-Psychologiques. 1992: 150(7):481-5.

[6] Aufderheide TP, Aprahamian C, Mateer JR, Rudnick E, Manchester EM, Lawrence SW, et al. Emergency airway management in hanging victims. Annals of Emergency Medicine. 1994; 24(5):879-84. [DOI:10.1016/S0196-0644(94)70206-3]

[7] DiMaio VJ, DiMaio D. Forensic pathology. Boca Raton: CRC Press; 2001.

[8] Saukko P, Knight B. Knight's forensic pathology. Boca Raton: CRC Press; 2004. [DOI:10.1201/b13642] 
[9] Adams N. Near hanging. Emergency Medicine. 1999; 11(1):17-21. [DOI:10.1046/j.1442-2026.1999.00314.x]

[10] Snowdon J. Suicide rates and methods in different age groups: Australian data and perceptions. International Journal of Geriatric Psychiatry. 1997; 12(2):253-8. [DOI:10.1002/ (SICI)1099-1166(199702)12:23.0.CO;2-L]

[11] Hawtdn K, Houston K, Shepperd R. Suicide in young people: study of 174 cases, aged under 25 years, based on coroners and medical records. The British Journal of Psychiatry. 1999; 175(3):271-6. [DOI:10.1192/bjp.175.3.271] [PMID]

[12] Wilkinson D, Gunnell D. Youth suicide trends in Australian metropolitan and non-metropolitan areas, 1988-1997. Australian \& New Zealand Journal of Psychiatry. 2000; 34(5):8228. [DOI:10.1046/j.1440-1614.2000.00812.x] [PMID]

[13] Nair S, Jacob J, Aaron S, Thomas M, Joseph M, Alexander M. Pulmonary distress following attempted suicidal hanging. Indian Journal of Medical Sciences. 2009; 63(2):53-7. [DOI:10.4103/0019-5359.49227] [PMID]

[14] Üzün İ, Büyük Y, Gürpinar K. Suicidal hanging: Fatalities in Istanbul retrospective analysis of 761 autopsy cases. Journal of Forensic and Legal Medicine. 2007; 14(7):406-9. [DOI:10.1016/j.jflm.2007.01.002] [PMID]

[15] Bayramoglu A, Saritemur M, GurST, Emet M. Demographic and clinical differences of aggressive and non-aggressive suicide attempts in the emergency department in the eastern region of Turkey. Iranian Red Crescent Medical Journal. 2015; 17(2):e24666. [DOI:10.5812/ircmj.24666] [PMID] [PMCID]

[16] Matsuyama T, Kitamura T, Kiyohara K, Hayashida S, Nitta $M$, Kawamura T, et al. Incidence and outcomes of emergency self-harm among adolescents: A descriptive epidemiological study in Osaka City, Japan. BMJ Open. 2016; 6:e011419. [DOI:10.1136/bmjopen-2016-011419] [PMID] [PMCID]

[17] Ambade VN, Kolpe D, Tumram N, Meshram S, Pawar M Kukde H. Characteristic features of hanging: A study in rural district of central India. Journal of Forensic Sciences. 2015; 60(5):1216-23. [DOI:10.1111/1556-4029.12772] [PMID]

[18] Ambade VN, Tumram N, Meshram S, Borkar J. Ligature material in hanging deaths: The neglected area in forensic examination. Egyptian Journal of Forensic Sciences. 2015; 5(3):109-13. [DOI:10.1016/j.ejfs.2014.07.002]

[19] Suarez-Penaranda JM, Alvarez T, Miguens X, RodriguezCalvo MS, de Abajo BL, Cortesao M, et al. Characterization of lesions in hanging deaths. Journal of Forensic Sciences. 2008; 53(3):720-3. [DOI:10.1111/j.1556-4029.2008.00700.x] [PMID]

[20] Lester D. Suicide and homicide in Costa Rica. Medicine, Science, and the Law. 1995; 35(4):316-8. [DOI:10.1177/00258 0249503500408] [PMID]

[21] Elfawal MA, Awad OA. Deaths from hanging in the eastern province of Saudi Arabia. Medicine, Science, and the Law. 1994; 34(4):307-12. [DOI:10.1177/002580249403400406] [PMID]

[22] Sane MR, Mugadlimath AB, Zine K, Farooqui JM, Phalke BJ. Course of near-hanging victims succumbed to death: a seven year study. Journal of Clinical and Diagnostic Research. 2015 9(3):HC01-HC03.

[DOI:10.7860/JCDR/2015/11189.5647]
[23] Matsuyama T, Okuchi K, Seki T, Murao Y. Prognostic factors in hanging injuries. The American Journal of Emergency Medicine. 2004; 22(3):207-10. [DOI:10.1016/j. ajem.2004.02.012] [PMID]

[24] Penney DJ, Stewart AH, Parr MJ. Prognostic outcome indicators following hanging injuries. Resuscitation. 2002; 54(1):27-9. [DOI:10.1016/S0300-9572(02)00050-3]

[25] Martin MJ, Weng J, Demetriades D, Salim A. Patterns of injury and functional outcome after hanging: Analysis of the National Trauma Data Bank. The American Journal of Surgery. 2005; 190(6):838-43. [DOI:10.1016/j.amjsurg.2005.05.051] [PMID]

[26] Salim A, Martin M, Sangthong B, Brown C, Rhee P, Demetriades D. Near-hanging injuries: A 10-year experience. Injury. 2006; 37(5):435-9. [DOI:10.1016/j.injury.2005.12.013] [PMID]

[27] Kasmaee VM, Zohrevandi B, Asadi P, Shakouri N. Nonjudicial hanging in Guilan Province, Iran between 2011 and 2013. Emergency. 2015; 3(4):155-8. [PMID] [PMCID] 